\title{
Molecular Changes Associated with Adaptation of Equine Influenza H3N8 Virus in Embryonated Chicken Eggs
}

\author{
Awlad Wadair Ali SAID ${ }^{1,2,3)}$, Michiko KODANI ${ }^{4)}$, Tatsufumi USUI ${ }^{1,2,5)}$, Yoshikazu FUJIMOTO ${ }^{2,5,6)}$, Toshihiro ITO ${ }^{2,5,6)}$ \\ and Tsuyoshi YAMAGUCHI ${ }^{1,2,5) *}$ \\ ${ }^{1)}$ Laboratory of Veterinary Hygiene, Department of Veterinary Medicine, Faculty of Agriculture, Tottori University, 4-101 Koyama- \\ Minami, Tottori 680-8553, ${ }^{2}$ Department of Infectious Diseases, United Graduate School of Veterinary Medicine, Yamaguchi University, \\ 1677-1 Yoshida, Yamaguchi 753-8515, Japan, ${ }^{3}$ Veterinary Research Centre, Ministry of Agriculture, P.O. Box, 1876, Code 111, Muscat, \\ Sultanate of Oman, ${ }^{4)}$ Tottori Prefecture, Kurayoshi Livestock Hygiene Service Center, 2-132 Seidani-cho Kurayoshi, Tottori 682-0017, \\ ${ }^{5)}$ The Avian Zoonosis Research Center, Tottori University, 4-101 Koyama-Minami, Tottori 680-8553 and ${ }^{6}$ Laboratory of Veterinary \\ Public Health, Department of Veterinary Medicine, Faculty of Agriculture, Tottori University, 4-101 Koyama-Minami, Tottori 680-8553, \\ Japan
}

(Received 16 November 2010/Accepted 24 November 2010/Published online in J-STAGE 8 December 2010)

\begin{abstract}
Embryonated chicken eggs (ECEs) are routinely used to isolate equine influenza virus. Propagation of the virus in ECEs results in selection of variants. In the present study, we determined nucleotide sequences of entire coding regions of parent $\mathrm{A} / \mathrm{equine} /$ Tottori/1/07 (H3N8) and its derivatives that have different passage histories in ECE. After 12 passages, nucleotide sequence analysis predicted 3 amino acid substitutions in hemagglutinin (HA; 2 in HA1 and 1 in HA2). The two amino acid substitutions in HA1 were located in the vicinity of the cell receptor-binding site. Three other amino acid substitutions were predicted in internal proteins, 1 in the M1, 1 in the NP and 1 in the PA. This is the first report showing mutations in the internal protein genes of equine influenza virus associated with adaptation to ECE.
\end{abstract}

KEY WORDS: egg adaptation, equine influenza virus, H3N8, molecular changes.

J.Vet.Med.Sci. 73(4): 545-548, 2011

Equine influenza virus, a member of the Orthomyxovirus family and Influenza A genus, contains eight segments of single-stranded negative sense RNA. These RNA segments are coated by nucleoprotein (NP), which along with a complex of polymerase, consists of PA, PB1 and PB2. The segments are bounded by matrix protein (M1), and the entire structure is covered by a lipid bilayer envelope. There are 2 kinds of surface glycoprotein, hemagglutinin (HA) and neuraminidase (NA). The HA molecule, consisting of HA1 and $\mathrm{HA} 2$, which are generated by proteolytic digestion of a premature HA molecule posttranslation, is responsible for attachment of the virus to the receptor molecule on the host cell. Two nonstructural proteins, NS1 and NS2, which contribute to virus replication, are found only in virusinfected cells and are not included in the virus particles.

Influenza A viruses have been isolated from a variety of animals [17]. Despite the wide range of hosts, most of these viruses have been isolated using embryonated chicken eggs (ECEs). In 1943, Burnet and Bull [1] reported that better growth of influenza viruses can be achieved with serial passages in the allantoic cavity of an ECE. Since then, serial passages of influenza viruses in ECEs have been routinely used for virus isolation. However, cultivation of influenza A viruses in the allantoic cavity of an ECE results in the selection of variants with amino acid substitutions. Furthermore, the amino acid substitutions during serial

\footnotetext{
* Correspondence to: Yamaguchi, T., The Avian Zoonosis Research Center, Faculty of Agriculture, Tottori University, 4101 Koyama-Minami, Tottori 680-8553, Japan.

e-mail: yamaguti@muses.tottori-u.ac.jp
}

passages in an ECE affect the antigenicity of the virus [10].

Equine influenza virus subtype $\mathrm{H} 3 \mathrm{~N} 8$ is routinely isolated from clinical samples using ECEs. ECE adaptation of equine influenza virus results in nucleotide sequence and deduced amino acid substitutions in the HA gene $[11,16]$. However, it is unclear whether mutations also occur in other genes. Adaptation of human influenza A virus to ECEs was found to result in mutations in viral genes other than the HA gene [23]. In 2007, A/equine/Tottori/1/07 (H3N8) was isolated during an equine outbreak in Tottori Prefecture, Japan. Initially, this virus grew poorly in the allantoic cavity of an ECE with a low hemagglutination titer, but acquired a higher titer after several passages.

In the present study, the nucleotide sequences of the entire coding regions of $\mathrm{A} /$ equine/Tottori/1/07 (H3N8) and derivatives of it having different passage histories in ECEs were determined, and their sequences were compared to define the amino acid substitutions associated with adaptation to ECEs.

Equine influenza virus A/equine/Tottori/1/07 (H3N8) was obtained from a sick horse in Tottori Prefecture, Japan. A nasal swab was suspended in phosphate buffered saline (PBS), and the suspension was inoculated to the allantoic cavity of 9- to 11-day-old ECEs. After incubation for 2 days at $37^{\circ} \mathrm{C}$, allantoic fluid was harvested and stored at $-80^{\circ} \mathrm{C}$ until use. Subsequently, the allantoic fluid was diluted 100 times with PBS and used as an inoculum for the next passage using ECEs. Three to four eggs were used in each passage. Subsequent passages were performed in the same way. The virus obtained from a nasal swab from the same 
horse but not passaged in ECEs was designated as the pass 0 virus. Viruses derived from pass 0 and subjected to additional passages in ECEs were designated as pass $\mathrm{N}$, where $\mathrm{N}$ represents the number of passages in ECEs.

Virus titers were determined by a hemagglutination test using chicken red blood cells according to the World Organization for Animal Health (OIE) Manual of Diagnostic Tests and Vaccines for Terrestrial Animals [15]. The infectivity titers of the viruses were determined as the $50 \%$ egg infective dose per $0.1 \mathrm{ml}\left(\mathrm{EID}_{50}\right)$ and $50 \%$ tissue culture infective dose per $0.1 \mathrm{~m} l\left(\right.$ TCID $\left._{50}\right)$ using Madin-Darby canine kidney (MDCK) cells as described previously [13].

For sequencing analysis, viral RNA was extracted from pass $0,5,8$ and 12 viruses using a Viral RNA extraction kit (QIAGEN Sciences, Germantown, MD, U.S.A.) according to the manufacturer's instructions. Subsequently, the RNA was transcribed into cDNA using a SuperScript III Reverse Transcriptase kit (Invitrogen, Carlsbad, CA, U.S.A.) according to the manufacturer's instructions. Uni.12 primer [8], which is specific for all 8 fragments of influenza A virus, was used for cDNA synthesis. Then the cDNA was used as the template for amplification of the virus genome by polymerase chain reaction (PCR). The 8 segments of the virus genome encoding HA (HA1 and HA2), NA, PB2, $\mathrm{PB} 1, \mathrm{PA}, \mathrm{NP}, \mathrm{M}$ (M1 and M2) and NS (NS1 and NS2) were amplified with primer pairs specific for each segment [8] by using GoTaq (Promega, San Luis Obispo, CA, U.S.A.). The nucleotide sequence of each PCR product was determined directly from the PCR products using a BigDye Ver3.1 kit (Applied Biosystems, Tokyo, Japan) and a 3130 Genetic Analyzer (Applied Biosystems) according to the manufacturer's instructions. The nucleotide sequences obtained were examined with BioEdit [7]. The locations of amino acid substitutions found in the HA molecule in three dimensional images were demonstrated with the RasMol viewer [18] using structural data of the HA molecule of a human H3 virus obtained from the Protein Data Bank (PDB code $2 \mathrm{HMG}$ ) [20].

Hemagglutination and infectivity titers of the viruses having different passage histories in ECEs are summarized in Table 1. The hemagglutination titers of pass 1 and 2 were less than 2, while those of the pass $3,4,5,8$ and 12 viruses were $4,8,8,2$ and 64 , respectively. The titers did not exceed 64 until 17 passages in ECEs. Virus titration using ECEs and MDCK cells showed that the infectivity titers of the viruses rose from $10^{2.5} \mathrm{EID}_{50}$ in pass 5 to $10^{7.32} \mathrm{EID}_{50}$ in pass 12 and from $10^{4.24} \mathrm{TCID}_{50}$ in pass 8 to $10^{6.48} \mathrm{TCID}_{50}$ in pass 12 . Hemagglutination and the infectivity titers tended to increase during the passages in ECEs.

The nucleotide sequences of the whole coding region of the equine influenza viruses from passes $0,5,8$ and 12 were determined. The nucleotide sequences of eight RNA segments of the pass 0 virus were deposited in the DNA Data Bank of Japan (accession numbers AB591842AB591849). Comparison of the nucleotide sequences of the whole coding region among the equine influenza viruses from passes $0,5,8$ and 12 revealed a total of 7 nucleotide substitutions in the coding regions of the surface protein of HA and internal proteins NP, M1 and PA (Table 1). The nucleotide at position 1,123 in NP in passes 5 and 12 and the nucleotide at position 1,027 in PA in pass 8 are shown as R because both $\mathrm{A}$ and $\mathrm{G}$ were found at these positions. Of the 7 nucleotide sequence changes, 3 amino acid substitutions found in HA at position 222 in pass 5, in M1 at position 224 and in PA at position 343 in pass 8 were conserved in the pass 12 virus. Two amino acid substitutions at positions 193 and 79 in HA1 and HA2, respectively, were found in the pass 12 virus.

In NP, the predicted amino acid at position 375 changed from a negatively charged amino acid Asp to uncharged amino acid Asn on pass 8 and to Ser (pass 12) or Gly (pass 12). NP plays an essential role in influenza virus replication

Table 1. The nucleotide and deduced amino acid sequence substitutions and viral titers of A/equine/Tottori/1/07 (H3N8) in the course of adaptation to embryonated chicken egg

\begin{tabular}{|c|c|c|c|c|c|c|c|c|c|c|}
\hline \multirow{3}{*}{$\begin{array}{c}\text { Passage } \\
\text { numbers in } \\
\text { ECE }\end{array}$} & \multicolumn{7}{|c|}{ Nucleotide and amino acid substitutions in viral genes ${ }^{\text {a) }}$} & \multicolumn{3}{|c|}{ Virus titer } \\
\hline & \multirow{2}{*}{$\begin{array}{c} \\
\mathrm{NP} \\
1,123 \\
(375)\end{array}$} & \multirow{2}{*}{$\begin{array}{l}\text { M1 } \\
670 \\
(224)\end{array}$} & \multicolumn{2}{|c|}{ PA } & \multicolumn{3}{|c|}{$\mathrm{HA}^{\mathrm{b})}$} & \multirow{2}{*}{$\begin{array}{c}\text { Hemaggl- } \\
\text { utination } \\
(\mathrm{HAU} / 0.05 \mathrm{~m} l)\end{array}$} & \multirow{2}{*}{$\begin{array}{c}\text { Infectivity } \\
\left(\log _{10} \mathrm{TCID}_{50} / 0.1 \mathrm{~m} l\right)\end{array}$} & \multirow{2}{*}{$\begin{array}{c}\text { Infectivity } \\
\left(\log _{10} \mathrm{EID}_{50} / 0.1 \mathrm{~m} l\right)\end{array}$} \\
\hline & & & $\begin{array}{l}1,027 \\
(343)\end{array}$ & $\begin{array}{l}1,993 \\
(665)\end{array}$ & $\begin{array}{c}\text { HA1 } \\
577 \\
(193)\end{array}$ & $\begin{array}{c}\text { HA1 } \\
664 \\
(222)\end{array}$ & $\begin{array}{l}\text { HA2 } \\
235 \\
(79)\end{array}$ & & & \\
\hline 0 & $\begin{array}{l}\text { GAT } \\
\text { Asp }\end{array}$ & $\begin{array}{c}\text { AGC } \\
\text { Ser }\end{array}$ & $\begin{array}{c}\text { GAA } \\
\text { Glu }\end{array}$ & $\begin{array}{l}\text { TTA } \\
\text { Leu }\end{array}$ & $\begin{array}{l}\text { AAA } \\
\text { Lys }\end{array}$ & $\begin{array}{l}\text { TGG } \\
\text { Trp }\end{array}$ & $\begin{array}{c}\text { GAC } \\
\text { Asp }\end{array}$ & $\mathrm{ND}^{\mathrm{c})}$ & ND & ND \\
\hline 5 & $\begin{array}{c}\text { RAT } \\
\text { Asp/Asn }\end{array}$ & $"$ & $"$ & $\begin{array}{l}\text { TTG } \\
\text { Leu }\end{array}$ & $"$ & $\begin{array}{l}\text { TTG } \\
\text { Leu }\end{array}$ & $"$ & 8 & ND & 2.5 \\
\hline 8 & $\begin{array}{l}\text { AAT } \\
\text { Asn }\end{array}$ & $\begin{array}{c}\mathrm{AGG} \\
\mathrm{Arg}\end{array}$ & $\begin{array}{c}\text { RAA } \\
\text { Glu / Lys }\end{array}$ & $"$ & $"$ & $"$ & $"$ & 2 & 4.24 & 5.23 \\
\hline 12 & $\begin{array}{c}\text { RGT } \\
\text { Ser/Gly }\end{array}$ & $"$ & $\begin{array}{l}\text { AAA } \\
\text { Lys }\end{array}$ & $"$ & $\begin{array}{c}\text { GAA } \\
\text { Glu }\end{array}$ & $"$ & $\begin{array}{c}\text { AAC } \\
\text { Asn }\end{array}$ & 64 & 6.48 & 7.32 \\
\hline
\end{tabular}

a) Numbers indicate the first nucleotide position and amino acid position (in parentheses). Ditto marks (") indicate the same sequence as the in row above. b) The amino acid numbering used for the H3 HA [25] was used. The signal peptides cleavage site is between the amino acid residues at positions -1 and +1 . c) ND $=$ Not done. 
[19]. The protein is localized in the nucleus in influenza virus-infected cells and is reported to have important roles in both viral assembly and RNA synthesis in the nucleus. So far, 3 nuclear localization signals (NLSs) essential for localization of NP to the nucleus have been found in NP [17]. The amino acid substitution found in this study was located in the third nuclear localization signal corresponding to amino acid positions 320 to 400 [21]. Furthermore, the amino acid residue at this position was reported to be specific to the host species [6] and may be related to the host specificity of the virus. Amino acid Asp residue found at this position in pass 0 was conserved in the most of the viruses isolated from equine, swine and avian species. The Gly residue found at this position in pass 12 is also found in some avian influenza viruses. In addition, a search of the NCBI database revealed that the Asn residue found at this position in the pass 5 and 8 viruses was conserved in most of the canine $\mathrm{H} 3$ viruses derived from equine $\mathrm{H} 3$ viruses in recent years. Although further research is needed, this mutation may affect the host specificity of the virus and may contribute to the adaptation of equine influenza virus in ECEs. Substitutions in other internal proteins include a Glu343-Lys substitution in PA and a Ser-224-Arg substitution in M1. Although the role of the PA protein in transcription and replication of the influenza virus genome is less well understood, PA is known as a key protein in the influenza virus polymerase complex consisting of $\mathrm{PA}, \mathrm{PB} 1$ and $\mathrm{PB} 2$ [9]. M1 protein is known as a multifunctional protein. It is associated with nuclear export of ribonucleic proteins (RNP) [22] and also plays a role in the viral budding process [5]. Both of the amino acid substitutions found in M1 and PA were from uncharged Ser and Glu to positively charged basic amino acids Arg and Lys, respectively. These changes may change the polarities of the entire proteins, which may affect the propagative properties of the virus in ECEs.

In the HA molecule, 3 amino acid substitutions were found, at 193 and 222 in HA1 and at 79 in HA2. Conformational location analysis by using a model of the three-dimensional structure of the HA complex showed that 2 amino acid substitutions at positions 193 and 222 in HA1 were located on the surface of the globular head of the HA molecule and in the vicinity of the receptor binding site, which has previously been reported [14]. Several amino acid substitutions were found to occur in the HA molecule of equine $\mathrm{H} 3 \mathrm{~N} 8$ virus following adaptation to MDCK cells and (or) ECEs $[11,16]$. The positions of these substitutions, although not identical to the ones we found, were also in the globular head and vicinity of the receptor binding site. Growth of influenza virus in egg can result in changes around the HA receptor-binding site, which can change the virus receptor-binding specificity [24]. Human influenza A viruses, when cultured in ECEs, remain specific for $\mathrm{SA} \alpha 2,6 \mathrm{Gal}$ receptors after 2 passages, but acquire specificity for SA $\alpha 2,3 \mathrm{Gal}$ receptors after additional passages [3]. Our results and the findings in previous reports mentioned above implied that the 2 amino acid substitutions in HA1 located in the vicinity of the cell receptor-binding site affect the receptor specificity of the virus. Ilobi et al. [10] reported an amino acid substitution position at 222 in HA1 from Trp to Gly associated with the adaptation of equine $\mathrm{H} 3 \mathrm{~N} 8$ to MDCK cells. Furthermore, when equine H3N8 virus was adapted to the dog, a Trp-to-Leu substitution occurred at this position [2], just as it did in the present study. Thus, the amino acid position at 222 of $\mathrm{HA}$ in the equine $\mathrm{H} 3 \mathrm{~N} 8$ virus may be critical for the host specificity of the virus. Another amino acid substitution position, 193 at the globular head of the HA molecule, is in the antigenic site B [12]. Because an amino acid substitution in HA associated with adaptation to ECE was found in a region that is critical for determining antigenicity, the propagation of equine H3N8 virus in ECEs for virus isolation or vaccine studies should be closely monitored to prevent changes in antigenicity.

Various HA subtypes of influenza viruses that have different virulences have distinct differences in the region near residues $68-79$ of the HA2 molecule [4]. Thus, the amino acid substitution found at position 79 of HA2 in this study, in addition to adapting the $\mathrm{H} 3 \mathrm{~N} 8$ virus to ECEs, may affect the virulence of the virus.

In summary, adaptation of equine influenza virus, $\mathrm{A} /$ equine/Tottori/1/07 (H3N8), to ECEs resulted in a total of six amino acid substitutions, not only in the surface protein $\mathrm{HA}$, which is known to be critical for receptor binding specificity, but also in the internal proteins, M1, NP and PA. This is the first report to reveal amino acid substitutions in the internal proteins of equine influenza H3N8 virus associated with adaptation of the virus to ECE.

ACKNOWLEDGMENTS. The first author was supported by a Monbukagakusho Scholarship of Japan for Ph.D. study, and all authors are grateful to the Ministry of Education, Culture, Sports, Science and Technology of Japan for financial support.

\section{REFERENCES}

1. Burnet, F. M. and Bull, D. R. 1943. Changes in influenza virus association with adaptation to passage in chick embryos. Aust. J. Exp. Biol. Med. Sci. 21: 55-69.

2. Crawford, P. C., Dubovi, E. J., Castleman, W. L., Stephenson, I. and Gibbs, E. P. 2005. Transmission of equine influenza virus to dogs. Science 310: 482-485.

3. Gambaryan, A. S., Robertson, J. S. and Matrosovich, M. N. 1999. Effects of egg-adaptation on the receptor-binding properties of human influenza A and B viruses. Virology 258: 232 239.

4. Goh, G. K., Dunker, A. K. and Uversky, V. N. 2009. Protein intrinsic disorder and influenza virulence: the 1918 H1N1 and H5N1 viruses. Virol. J. 6: 69.

5. Gomez-Puertas, P., Albo, C., Perez-Pastrana, E., Vivo, A. and Portela, A. 2000. Influenza virus matrix protein is the major driving force in virus budding. J. Virol. 74: 11538-11547.

6. Gorman, O. T., Bean, W. J., Kawaoka, Y. and Webster, R. G. 1990. Evolution of the nucleoprotein gene of influenza A virus. J. Virol. 64: 1487-1497.

7. Hall, A. 1999. BioEdit: a user-friendly biological sequence alignment editor and analysis program for Windows 95/98/NT. 
Nucleic Acids Symp. Ser. 41: 95-98.

8. Hoffmann, E., Stech, J., Guan, Y., Webster, R. G. and Perez, D. R. 2001. Universal primer set for the full-length amplification of all influenza A viruses. Arch. Virol. 146: 2275-2289.

9. Huarte, M., Falcon, A., Nakaya, Y., Ortin, J., Garcia-Sastre, A. and Nieto, A. 2003. Threonine 157 of Influenza Virus PA Polymerase Subunit Modulates RNA Replication in Infectious Viruses. J. Virol. 77: 60007-60013.

10. Ilobi, C. P., Henfrey, R., Robertson, J. S., Mumford, J. A., Erasmus, B. J. and Wood, J. M. 1994. Antigenic and molecular characterization of host cell-mediated variants of equine $\mathrm{H} 3 \mathrm{~N} 8$ influenza viruses. J. Gen. Virol. 75: 669-673.

11. Ilobi, C. P., Nicolson, C., Taylor, J., Mumford, J. A., Wood, J. M. and Robertson, J. S. 1998. Direct sequencing of the HA gene of clinical equine H3N8 influenza virus and comparison with laboratory derived viruses. Arch. Virol. 143: 891-901.

12. Lai, A. C., Chambers, T. M., Holland, R. E. Jr., Morley, P. S. and Haines, D. M. 2001. Diverged evolution of recent equine-2 influenza (H3N8) viruses in the Western Hemisphere. Arch. Virol. 146: 1063-1074.

13. Lugovtsev, V. Y., Vodeiko, G. M. and Levandowski, R. A. 2005. Mutational pattern of influenza B viruses adapted to high growth replication in embryonated eggs. Virus Res. 109: 149157.

14. Nobusawa, E., Aoyama, T., Kato, H., Suzuki, Y., Tateno, Y. and Nakajima, K. 1991. Comparison of complete amino acid sequences and receptor-binding properties among 13 serotypes of hemagglutinins of influenza A viruses. Virology 182: 475485.

15. OIE. 2008. Avian influenza. pp. 465-481. In: Manual of Standards for Diagnostic Tests and Vaccines, 6th ed., Office International des Epizooties, Paris.
16. Oxburgh, L. and Klingeborn, B. 1999. Cocirculation of two distinct lineages of equine influenza virus subtype H3N8. J. Clin. Microbiol. 37: 3005-3009.

17. Palese, P. and Shaw, M. L. 2007. Orthomyxoviridae: the viruses and their replication. pp. 1647-1689. In: Fields Virology, 5th ed. (Knipe, D. M. and Howley, P. M. eds.), Lippincott Williams and Wilkins, Philadelphia.

18. Sayle, R. A. and Milner-White, E. J. 1995. RASMOL: biomolecular graphics for all. Trends Biochem. Sci. 20: 374-376.

19. Skorko, R., Summers, D. F. and Galarza, J. M. 1991. Influenza A virus in vitro transcription: roles of NS1 and NP proteins in regulating RNA synthesis. Virology 180: 668-677.

20. Weis, W. I., Brünger, A. T., Skehel, J. J. and Wiley, D. C. 1990. Refinement of the influenza virus hemagglutinin by simulated annealing. J. Mol. Biol. 20: 737-761.

21. Wang, P., Palese, P. and O'Neill, R. E. 1997. The NPI-1/NPI-3 (karyopherin alpha) binding site on the influenza a virus nucleoprotein NP is a nonconventional nuclear localization signal. $J$. Virol. 71: 1850-1856.

22. Whittaker, G., Bui, M. and Helenius, A. 1996. The role of nuclear import and export in influenza virus infection. Trends Cell Biol. 6: 67-71.

23. Widjaja, L., Ilyushina, N., Webster, R. G. and Webby, R. J. 2006. Molecular changes associated with adaptation of human influenza A virus in embryonated chicken eggs. Virology 350: 137-145.

24. Williams, S. P. and Robertson, J. S. 1993. Analysis of the restriction to the growth of nonegg-adapted human influenza virus in eggs. Virology 196: 660-665.

25. Wilson, I. A., Skehel, J. J. and Wiley, D. C. 1981. Structure of the haemagglutinin membrane glycoprotein of influenza virus at $3 \AA$ resolution. Nature 289: 366-373. 